\title{
Encauzar el conocimiento de la ciencia y la tecnología
}

\author{
OLIVÉ, LEÓN (2000), EL BIEN, EL MAL Y LA RAZÓN: FACETAS DE LAS \\ CiEnCIAS Y la teCnOlogía, Paidós-Universidad Nacional AutónOma \\ DE MÉXICO, MÉXICO D.F., 162 PP., ISBN: 9688534536.
}

\section{Introducción}

En los inicios del siglo xx era común hablar de ciencia, técnica y tecnología como conceptos claramente diferenciados. Pero para finales de siglo e inicio de un nuevo lustro, nos damos cuenta de que al hablar de tecnología es inevitable relacionar este campo de estudio con los otros anteriormente mencionados; incluso se usa la palabra "tecnociencia" para evidenciar el hecho de su fusión. Este acontecimiento estuvo marcado por la revolución tecnológica y la informática, campos de investigación que han modificado la base material de la ciudad y transformado el espacio social del ser humano.

Hablamos de un cambio tan vertiginoso que ha empezado a afectar la noción de la realidad condicionando las relaciones sociales y laborales. Por tal motivo, el ejercicio de reflexionar sobre la ciencia y la tecnología, así como sobre sus implicaciones, ha adquirido un gran auge. En efecto, la posibilidad de encontrar textos que traten cuestiones relacionadas con la filosofía de la ciencia, la historia de la técnica o la historia del conocimiento, de epistemología, economía del conocimiento o sociología del conocimiento es un hecho reciente. Las dos últimas áreas mencionadas han acrecentado el escepticismo de aquellos que plantean que el conocimiento siempre ha estado en el núcleo del desarrollo económico.

Sobre este problema de apreciación, y sobre muchos otros, León Olivé nos invita a reconocer y superar uno de los principales obstáculos de los análisis que se realizan en torno a la filosofía de la ciencia o al conocimiento, que resume en la "unidimensionalidad y descontextualización" de muchos documentos de investigación al volverse temas en boga; análisis que pretenden establecer "la respuesta correcta" o "la única verdad", así lo ex- 
presa el autor, sin hacer referencia a sus marcos conceptuales y contextuales existentes.

Este libro, dividido en tres partes, explora la imagen de la ciencia, el bien, el mal, la razón y, por último, la racionalidad y el pluralismo en la ciencia. Podemos decir que en este documento el autor, con un lenguaje fresco, propositivo, nos lleva a comprender este fenómeno virtual y virtuoso del entendimiento de la tecnociencia.

\section{La imagen de la ciencia}

En el siglo xx, la teoría del conocimiento progresó conforme el conocimiento se hizo más confiable, ayudada sin duda por las diferentes formas en que se vinculó con otras disciplinas filosóficas. Olivé menciona que ese progreso puede atribuirse tanto a la distensión en las pretensiones normativas como al hecho de que la discusión se ha centrado en los procedimientos de generación, cambio, desarrollo y difusión del conocimiento. Asimismo, destaca que el reconocimiento de diversas vías para conocer el mundo, que pueden reclamar legitimidad en términos epistémicos o de eficiencia, ha posibilitado ese progreso.

A partir del planteamiento de diez tesis, el autor establece lo que denomina proceso de naturalización de las disciplinas ocupadas en la ciencia del conocimiento; menciona también que el progreso en la ciencia radica en que hemos aprendido mejor a aprender, y esto es una tendencia continua. Podemos hacer mejores predicciones y manipulamos fenómenos de manera más precisa. Pero también sabemos mejor cómo investigar. Las diez tesis son:

1. Ha habido progreso en el conocimiento.

2. Gran parte del progreso en la ciencia radica en que actualmente sabemos más del mundo y también de la forma en que lo conocemos, razón por la cual ha sido preciso matizar muchas ideas que teníamos sobre el quehacer científico.

3. Particularmente ha progresado nuestra concepción de lo que es progreso en el conocimiento y en la ciencia.

4. El avance se muestra en el abandono o suspensión de la búsqueda de fundamentos últimos.

5. Se ha progresado en la medida que se han relajado las pretensiones normativas y la discusión se ha centrado en los procedimientos de generación, cambio, desarrollo y difu- 
sión del conocimiento; es decir, en la medida que el conocimiento se ha naturalizado.

6. El progreso en el siglo xx ha sido posible mediante el reconocimiento de la existencia de diversas vías para conocer el mundo, que pueden reclamar legitimidad en términos epistémicos o de eficiencia.

7. El desarrollo del conocimiento se ha logrado mediante consensos.

8. A un consenso le precede una controversia, y ésta constituye un factor esencial de la actividad científica.

9. La naturalización de la epistemología y filosofía de la ciencia ha exigido un análisis de la racionalidad científica: procedimientos, principios, normas, reglas y conceptos.

10. Los acuerdos y consensos se consolidan y adquieren validez al formar parte de tradiciones encarnadas en las comunidades.

Las anteriores tesis expuestas son complementadas por tres más, que tienen que ver con el papel social y cultural y que hacen referencia a tres imágenes que deben ser entendidas para aprehender las características y complejidad del conocimiento:

I) La imagen filosófica.

II) La imagen científica de la ciencia.

III) La imagen social de la ciencia.

En este planteamiento, donde los supuestos son conocidos o innegables, no acontece un artilugio gramatical mal planteado; significa algo más: un reconocimiento, por ejemplo, a la dicotomía, que no es sinónimo de diferencia respecto a su sujeto, a la epistemología, a la filosofía o las diversas posturas existentes en el mundo, en el sentido estricto del razonamiento. Existe un punto destacable: el manejo de "la imagen", entendiendo cómo se edifican las percepciones del ser humano sobre la tecnología y la ciencia, donde lo importante no es la imagen que es simulacrum, sino cómo se construye o concibe.

\section{El bien, el mal y la razón}

Por medio de dos postulados Olivé plantea algunas facetas de la ciencia y la tecnología. Traza algunos problemas éticos, de apreciación, de planteamiento, o contrapone, en un sentido analógi- 
co, un proceso. El primer postulado dice: "La ciencia y la tecnología, por sí mismas, no plantean ningún problema ético. En todo caso, las que pueden ser buenas o malas desde el punto de vista moral son las aplicaciones de los conocimientos científicos y de la tecnología” (p. 83).

El segundo postulado establece que "ni la ciencia ni la tecnología son indiferentes al bien y mal” (p. 83). Después, el autor nos sitúa en el eje del análisis al mencionar que investigando los valores y las normas en la ciencia y la tecnología realiza su acercamiento a un problema particularmente ético, y establece las razones por las cuales los científicos, los tecnólogos e incluso la sociedad tienen responsabilidades morales frente a la investigación científica y tecnológica, su desarrollo y sus aplicaciones.

Propone la evaluación de los sistemas técnicos en dos niveles: la evaluación interna gira en torno al concepto de eficiencia y otros como factibilidad, eficacia y fiabilidad. La evaluación externa tiene que ver con el contexto social y cultural. En este apartado, Olivé se concentra en el análisis de la evaluación y deseabilidad de las innovaciones tecnológicas y del desarrollo tecnológico desde la perspectiva del contexto social amplio al cual afecta la aplicación de los sistemas técnicos ahí insertos. Menciona que la observación y evaluación de estos procesos es la mejor manera de conocer el progreso del conocimiento, la ciencia, la tecnología, la moral y la sociedad en su conjunto (la consecuencia y el daño).

\section{La racionalidad y el pluralismo de la ciencia}

Al plantear los problemas metodológicos y epistemológicos, Olivé explica algunos conceptos en los que se sustenta su obra. De ellos entiende el pluralismo como una concepción coherente, capaz de dar cuenta de la diversidad que existe en la ciencia y en su desarrollo, de los diferentes puntos de vista de la ciencia, y que es extrapolable a otras entidades que generan conocimiento.

Argumenta que, como consecuencia de la tesis pluralista, no hay una única vía legítima hacia el conocimiento científico y hacia el logro de metas específicas, pues existe una amplia gama de caminos; el progreso de la ciencia, por tanto, no puede evaluarse desde un único punto de vista. Este planteamiento responde a la concepción de Larry Laudan, quien ha contribuido desde los años sesenta a cambiar el panorama en la epistemología y la filosofía de la ciencia, en particular en la teoría pluralista de la ciencia. 
En este apartado, Olivé inicia la discusión de una concepción pluralista de la ciencia examinando sus fundamentos en una epistemología pluralista, y mediante los conceptos epistémicos básicos de racionalidad, explora su relación con el progreso científico. Los temas tratados son: la ciencia y el progreso científico, la visión hegeliana, la racionalidad y el progreso, el papel normativo de la epistemología, racionalidad, objetividad y verdad, el modelo clásico de la racionalidad y el constructivismo.

\section{Conclusiones}

La discusión en el ámbito de la filosofía de la ciencia y de la epistemología no corresponde sólo a los 'iniciados'; por el contrario, es una herramienta esencial sin la cual difícilmente podrá entenderse la complejidad continuamente renovada del mundo social y cultural. En este sentido, el pluralismo -propuesto por Olivé- permite superar la visión dicotómica, polar y reduccionista con la cual hemos constituido la ética, política y cultura. Otra referencia para considerar es la expuesta por Peter Burke, quien plantea su análisis desde la parte social del conocimiento, objetivo que reduce a la desfamiliarización: "Sería deseable conseguir lo que el crítico ruso Victor Shklovsky describió en el término ostranenie, un tipo de distanciamiento que hace que lo familiar parezca extraño y lo natural arbitrario" (Burke, 2002: 13).

Este trabajo no se mantiene sólo en el nivel de análisis de los problemas epistemológicos, sino que examina la organización social de la ciencia, es decir, proporciona diversas herramientas para reflexionar sobre la conformación y organización de diferentes grupos de científicos y su influencia en la concepción de lo 'que es' o 'debe ser' el mundo. Este planteamiento, me parece, va más allá, del esquema presentado por Mario Bunge, en el cual establece un sistema para entender el desarrollo científico (Bunge, 2004: 227233), pues sugiere no sólo una propuesta para el conocimiento, sino también la dirección para la ética, la política y la cultura.

Existe un planteamiento que no quiero dejar pasar, y es lo que postula Olivé en lo referente a idea y creencia. Indica que al aceptarse de forma racional una creencia, ésta se convierte en saber. Tal ejercicio requiere una condición racional y lógica, pues, según el autor, es el proceso mediante el cual la creencia es aceptada como verdadera. Aun releyendo este párrafo, parece poco sólido. Pero encuentro mejor planteamiento en Ortega y Gasset: 
Cuando se intenta determinar cuáles son las ideas de un hombre o de una época solemos confundir dos cosas radicalmente distintas: sus creencias y sus ocurrencias o pensamientos. En rigor sólo estas últimas deben llamarse ideas. [...] Toda nuestra conducta, incluso la intelectual, depende de cuál sea el sistema de nuestras creencias auténticas. En ellas vivimos, nos movemos y somos. [...] En cambio, las ideas, es decir, los pensamientos que tenemos sobre las cosas, sean originales o recibidos, no poseen en nuestra vida valor de realidad. Actúan en ella precisamente como pensamientos nuestros y sólo como tales. La verdad o falsedad de una idea es una cuestión de "política interior" dentro del mundo imaginario de nuestras ideas. En las ideas somos, en las creencias estamos (Ortega y Gasset, 2001: 23-34).

Esta aproximación nos ayuda a entender la utilización del término "imágenes" en relación con algunas representaciones que el autor realiza; es decir, en la dirección de cuestionar qué se estudia, qué se produce y qué se construye. Esto significa que la vida intelectual es secundaria a la vida real o auténtica, y representa en ésta sólo una visión virtual o imaginaria, donde lo importante no es la imagen en sí, sino entender a qué respondemos, a qué debemos nuestros actos y reacciones, dónde se sustentan nuestras ideas y encauzar las formas en que se edifican o construyen las percepciones sobre aquello que estudia la ciencia, sus formas de trabajo y la manera en que se distribuye y legitima el conocimiento.

\section{Bibliografía}

Bunge, Mario (2004), Epistemología, $4^{\mathrm{a}}$ ed., Siglo xxi Editores, México.

Burke, Peter (2002), Historia social del conocimiento: de Gutenberg a Diderot, Paidós, Barcelona.

Ortega y Gasset, José (2001), Ideas y creencias, Alianza Editorial, Madrid.

José Tapia Blanco

Colegio Nacional de Planificadores del Desarrollo Urbano

Sustentable, A.c. Correo-e: joset_22@yahoo.com.mx y vicepresidente@conpladeus.com. 
José Tapia Blanco estudia el Doctorado en Ciencias y Artes para el Diseño, con el área de especialización en investigación y gestión territorial, en la Universidad Autónoma Metropolitana, unidad Xochimilco. Es investigador del Programa de Estudios Metropolitanos (PUEM) de esa universidad y vicepresidente del Colegio Nacional de Planificadores del Desarrollo Urbano Sustentable, A.C. 